\title{
THE VALUE OF SERUM REACTIONS IN THE DIAGNOSIS AND TREATMENT OF VENEREAL DISEASE
}

By Dr. T. E. OSMOND

\section{Discussion}

Dr. ORPWOOD PRICE said he was sure it would be agreed that Dr. Osmond had presented a most excellent paper, from which a great deal could be learned.

With regard to serum tests for syphilis, he was of Dr. Osmond's opinion that the Wassermann, if rightly interpreted, was the best test; the Kahn the speaker regarded as a confirmatory test, the Sigma he used in difficult cases, in which one wanted to know what was the effect of treatment, or in cases which gave a negative Wassermann and a persistently positive Kahn in spite of much treatment. In early untreated cases of syphilis it was his experience that the Kahn tended to become positive sooner than the Wassermann. At the other end of the scale a well-treated patient giving a negative Wassermann and showing no sign of syphilis gave, in a few instances, a persistently positive Kahn which could not be regarded as other than a false positive reaction. In regard to the cerebro-spinal fluid, he urged upon all clinicians that a cell count was essential, and this could not be done accurately unless the fluid was transferred to the laboratory without delay. A cell count done after an interval of twenty-four hours was valueless.

With regard to the complement-fixation test for gonorrhœa, he could not agree with all Dr. Osmond's views about the possibility of cross-fixation with the anti-bodies of $M$. catarrhalis. The frequency with which this might occur appeared to be overstressed, and in any case it yet remained to be proved that a cross-fixation reaction occurred in such a strength as to detract from the value of the test. Should any doubt arise he maintained that it could be dealt with satisfactorily by means of quantita- 


\section{BRITISH JOURNAL OF VENEREAL DISEASES}

tive parallel reactions using gonococcal and catarrhalis antigens.

As to cases which gave persistently positive reactions with the gonococcal complement-fixation test in the absence of any clinical signs, these people did marry, and after marriage often neither partner showed any sign of the disease. Furthermore, the offspring of the union appeared to be quite healthy children. But he thought most members would agree that it was a common experience that if one of the partners went outside the union there was often a flare up of the disease. From these clinical facts it would appear that much work on the pathogenicity of the gonococcus remains to be done.

Mr. Ambrose KING also congratulated Dr. Osmond on his admirable paper, and wished to record three respects in which his experience with the complementfixation test had not been parallel with his (the lecturer's). Dr. Osmond seemed to indicate that it was common for the complement-fixation test to remain positive after the patient was cured, but that had not been the speaker's experience; he would say that the almost invariable rule was for the test to become negative weeks before the patient could be passed as cured by clinical, microscopical and cultural tests.

The second point was the question of the apparently cured patient with a persistently positive complementfixation test. Mr. King's own belief was that in such cases if the patient was investigated clinically, culturally, and in every possible way, that ultimately some focus of infection would be found to account for that persistently positive report. And he thought that those patients infected their partners in marriage, or any other partners they might have, though apparently they were cured of their disease. He thought that in such patients their continued positive fixation test was an indication of toxic absorption. They were the patients who, in after yearsperhaps after many years-would develop intractable late metastatic lesions of gonorrhœa. Those who gave a history of gonorrhœa for which apparently they had been adequately treated came later with such a lesion as iritis or arthritis, and the fixation test was positive, and investigation showed that gonococci were present.

His third point concerned the occurrence of subacute gonococcal arthritis; he understood Dr. Osmond to say 


\section{THE VALUE OF SERUM REACTIONS}

that in such cases the fixation test was always positive. The speaker had found a certain number of cases in which the patient had such a lesion and it could be demonstrated that gonococcal infection was present, both by clinical examination and by cultural tests. Usually such lesions would clear up under appropriate treatment, which generally included vaccines. Sometimes the result of the fixation test was negative when the patient was first seen.

Mr. Hamish Nicol expressed his appreciation of Dr. Osmond's paper.

Dr. Osmond had spoken of sero-negative primary syphilis and sero-positive primary syphilis; some years ago Drs. MacCormac and Kennaway, of the Middlesex Hospital, published a paper which went to show that many sero-negative primary syphilitic cases become seropositive during treatment. This was shown by taking the blood W.R. each week.

He would like to know if the opener had made weekly blood tests, and, if so, did his findings coincide with those of Drs. MacCormac and Kennaway?

Colonel L. W. HARRISON said he was specially interested to note that the Wassermann test was still holding its own, because a few years ago it seemed as if its days were numbered. The position of the Wassermann test had been strengthened since then, and Dr. Osmond had to-night spoken of modifications that rendered it more delicate than even the flocculation test.

With regard to the interpretation of the persistently positive gonococcal complement-fixation reaction, one man said such a patient was always a harbourer of the gonococcus, while others said they did not believe that this was invariably the case. Mr. King had just said that, if looked for properly, the gonococcus would be found in all such patients eventually-a remark which was not very complimentary to Dr. Osmond.

Another thing which worried the speaker was the statement by Dr. Orpwood Price that if the complementfixation had been evoked by vaccine alone, it would disappear in six weeks. During the War, when Dr. Thomson was working on his detoxicated vaccine at Rochester Row, the speaker was interested to see whether it would evoke a positive complement-fixation in a normal subject and submitted himself to a series of 


\section{BRITISH JOURNAL OF VENEREAL DISEASES}

injections. The gonococcal fixation reaction increased, and eventually after suspension of the injections it remained positive for three months. There had been much other evidence to show that the gonococcal complement-fixation reaction persisted longer than for six or seven weeks after it had been evoked only by vaccine. There was experience at the St. Thomas's clinic of the gonococcal complement-fixation reaction being evoked not by gonococcal vaccine but by the antiDucrey's bacillus vaccine known as Dmelcos. A recent example of this was a patient admitted for granuloma venereum. He was tested as a matter of routine when he first attended and found to have a positive Wassermann but a negative gonococcal complement-fixation reaction. As the case was at first thought to be one of soft chancre the patient received a number of injections of Dmelcos, and his blood serum was afterwards found to give a strongly positive gonococcal complement-fixation reaction in a $\mathrm{I}$ in 40 dilution. That reaction still seemed to be as strong as ever three months after stopping the injections. In the face of evidence of that kind, caution was desirable before making definite statements about the inference to be drawn from a persistent gonococcal fixation reaction. He had no intention of belittling the test, but no good would come of exaggerated statements about it.

Dr. Lynette Hemmant also wished to thank Dr. Osmond for his paper ; it had taught her a lot, and had strengthened her in her view about the value of the complement-fixation tests, especially in the treatment of gonorrhœa in women. When films were indefinite and a culture was not to be had, one fell back thankfully on reports of complement-fixation tests, and if it was not possible to fall back on the latter it was unsatisfactory for doctor and patient. If the test could be standardised in clinics, there would be fewer cases of women continuing treatment year after year with nothing definite in their film reports. At King's she had had two cases recently with histories of having attended other clinics for several years, when no definite diagnosis had been made. She could not speak too highly of the value of the complement-fixation test, as she had experienced it.

Dr. David Nabarro said he had listened to Dr. Osmond's paper with the greatest interest, and agreed with many of the things that gentleman said. 


\section{THE VALUE OF SERUM REACTIONS}

With regard to the "weak positive" cases, he remembered the time when it was said that no notice should be taken of weak positives, but with that view he had never agreed, because in cases of congenital syphilis one might find the Wassermann weakly positive. Such a result always stimulated him to make a further critical examination of the case. He remembered particularly one child with nephritis, who returned a feeble positive, and on going into the case more thoroughly he ascertained that there was a definite syphilitic history, and he induced the physician to allow some treatment to be given on that finding. After a little treatment the Wassermann became strongly positive, and eventually it was negative. If he had not thought of the possibility of that being a syphilitic case the nature of it would have been missed, because the clinicians had not suspected the nephritis being of a syphilitic nature.

He regarded the Kahn as a helpful confirmatory test ; it was being a good deal used in his clinic. According to Colonel Harrison's criticisms of recent comparative tests done in Dr. Wyler's and in his (Dr. Nabarro's) laboratory, his Kahns were rather too strong. At his clinic recently there was a case with a four-plus Kahn, the history was thoroughly gone into, and a provocative injection was given, but without making it positive Wassermann, yet the Kahn was positive. He concluded it was probably a syphilitic case. On the whole, the staff at his clinic were very pleased with the Kahn test, and it was noted to remain positive longer than did the Wassermann.

Some years ago he did a blood Wassermann in an obscure nerve case and it was negative. Examination of the cerebro-spinal fluid showed signs of tabes. If one did a Kahn or other flocculation test with a Wassermann, it would sometimes put one on the right track when a Wassermann alone would lead one to think the case was cured.

He did not quite follow what Dr. Osmond said concerning the Wassermann in pregnancy, but books stated that during pregnancy the Wassermann test was unreliable, and was often negative in syphilitic women. $\mathrm{He}$, the speaker, had found it positive in many of the cases he examined, and even in pregnancy it was valuable to test the mother's blood for a positive Wassermann.

He did not agree with all that Dr. Osmond said as to 


\section{BRITISH JOURNAL OF VENEREAL DISEASES}

congenital syphilis and the Wassermann test. Some books stated that often at puberty the Wassermann tended to become negative without treatment. $\mathrm{He}$ supposed that nowadays that was not allowed to happen. In the treatment of congenital syphilitics it was often necessary to continue for years before the Wassermann became negative ; occasionally a case would be met with which never became negative.

With regard to Wassermann fastness and giving treatment every year, he had the case of a lady now 93 years of age who had a positive Wasserman, and the disease had not killed her yet. He was not sure it meant that she had still active spirochætes in her body.

With regard to cases of vulvo-vaginitis and the gonococcus complement-fixation test, that test was tried in all the cases at the clinic, but it was not a very strong reaction. Ocasionally it was stronger in the presence of arthritis, but in his clinic he did not find that the test helped very much ; a Wassermann was always done in vaginitis cases as there was the possibility of syphilis being present as well as gonorrhœa.

Dr. ANwyl DAvies also expressed his high appreciation of Dr. Osmond's paper; it was always worth while to listen to a man who had had such an enormous experience; sometimes he wished he were himself a pathologist so that he could argue more thoroughly about these things.

He was pleased to hear Dr. Osmond say that acute fevers, such as pneumonia and scarlet fever, could give a positive Wassermann, but not if the test were properly done. But three or four years ago at the London Hospital an epidemic of glandular fever occurred, and the London Hospital laboratories obtained positive Wassermanns in those cases. He thought it a possible explanation that some of the cases were congenital syphilitics; he examined a number of them, but without being able to find evidence of this. He had to admit that glandular fever could yield a positive Wassermann, as these results were confirmed in his own laboratory at the Whitechapel Clinic.

He agreed with Dr. Nabarro's remark about the Kahn test. As a clinician, he found the Kahn test of more value, both in early and late treated cases, than the Wassermann. If a man were in the Colonies and could 


\section{THE VALUE OF SERUM REACTIONS}

do only one test, he would like to know from Dr. Osmond whether the test should be a Kahn or a Wassermann.

He had proved to his own satisfaction that cases of secondary syphilis existed in which the spirochæte had been found and yet the Wassermann was persistently negative.

Dr. Osmond had said that patients with a Wassermannfast reaction should have their cerebro-spinal fluid examined. With that the speaker agreed; it was always an advantage for the clinician to have the results of cerebro-spinal fluid examinations on his desk. But what additional treatment apart from malaria should be used on such patients?

With regard to the gonococcal fixation test, a little time ago he had correspondence with Professor Oppenheim of Vienna, who wrote the speaker about a case both were interested in. The Professor said that though the man had a positive gonococcal complement-fixation he thought the infection had disappeared. He, Dr. Davies, cultured the gonococcus from the Professor's own case. He thought that in the majority of male cases one could culture the gonococcus, which was generally tucked away in the vesicles. He thought the solution of those cases with a persistently positive reaction was that, sealed away somewhere, the gonococcus was still present. A fortnight ago he had the case of a man who had been married six years and suddenly developed a discharge. His wife, who had been pregnant, was free of gonococci, yet gonococci were grown from the husband's seminal vesicles. In that case he satisfied himself that it was not a further infection. Years before marriage that man had had gonorrhœa.

He agreed with Dr. Osmond's last remark, that laboratory tests should be one's servants, not one's masters.

Dr. Buckley Sharp confirmed Dr. Anwyl Davies' remark as to the occurrence of sero-negative secondary syphilis, of which he had seen a few cases. One he had at present was persistently negative to begin with and responded to treatment, clinically the Wassermann remaining negative. He had what the speaker regarded as a full amount of treatment, and at the end of that time he had an epileptiform seizure, and the cerebrospinal fluid was strongly positive. Presumably his negative Wassermann was due to his own failure to 


\section{BRITISH JOURNAL OF VENEREAL DISEASES}

react and produce the necessary immunity to his own infection. He had seen a case of sero-negative syphilis which did not respond to treatment at all until, by devious means, his Wassermann was rendered positive, and then the rash cleared up under treatment.

The PRESIDENT remarked that she was very glad to hear Dr. Osmond say that the Wassermann of a congenitally syphilitic baby early in life was frequently negative, becoming positive later. That she had proved for herself time and again in her department. In the case of a mother who had had inadequate treatment in pregnancy and the child was born free of external lesions, a report of a negative Wassermann was not worth the paper it was written on, as sooner or later, unless adequately treated, such child would develop definite lesions, as well as give a positive Wassermann. If mother and child were removed to hospital with intercurrent disease, the child at the post-mortem would be found to have spirochætes in liver and spleen. What she understood Dr. Osmond to say in regard to the Wassermann test in pregnancy was, that some writers and speakers said that a false positive might be obtained in pregnancy, but Dr. Osmond believed, on the contrary, that a certain number of cases of conceptional syphilis gave a negative Wassermann. (Dr. Osmond : Yes.) That was what she also had found clinically. At the Johns Hopkins 5 per cent. gave a negative Wassermann in pregnancy, this figure including both white and coloured women. The President did not think the figure reached 5 per cent. in this country. In her department a very small number of cases seen in pregnancy with gonorrhœa, and giving a negative Wassermann giving no history of syphilis, in due course delivered themselves of syphilitic children.

With regard to Wassermann testing of the cord, Dr. Rorke said she was glad to hear Dr. Osmond say he did not think well of that. She herself regarded it as of no value; the Wassermann in the cord was practically the same as the mother's Wassermann. At one time, at the Royal Free Hospital, there was a vogue for taking the cord blood of every child for testing-not in her own department-and it was carried out in 200 cases, but she did not think the results were of any value. She always preferred the Wassermann taken in the new-born child a few days after it was born, and in every case repeated a

$$
\text { Ig } 8
$$




\section{THE VALUE OF SERUM REACTIONS}

few weeks later, unless the finding was what would be expected from the amount of treatment which the mother had received.

It had been news to her to-night that in some cases of persistently positive Wassermann the Sigma test might give a differential result. She had thought the Kahn the most often used of the flocculation tests, the others being " also rans." The Sigma might be useful for congenital syphilitics. She had seen a number of these children, who were sent in at seven or eight years of age or later with interstitial keratitis, who reacted very well to treatment, who had been brought regularly for treatment, yet whose Wassermann and Kahn never altered a bit. She had two or three such children at the present time, doing well, having no eye relapses, and gaining scholarships at school, and comparing favourably with other children, yet the Wassermann reaction remaining unmoved by any treatment. Therefore, she might ask the pathologist to do a few Sigma tests.

The complement-fixation test she regarded as of the greatest value. She was not a pathologist, but she considered it must be a tricky test, because a positive reaction was wrongly produced, more often so than it should be. In the laboratory of her hospital there had been considerable trouble at one period with the return of endless positives in cases in which positives were not expected and in which every other test showed that the condition was not gonorrhœa. These false positives were now very much more rare, owing to alteration in technique of test.

Dr. Osmond, in reply, said it had seemed to him that there were two points about his paper which were very obvious.

One was a point on which he had failed signally to make himself clear to most of his hearers, and for which he apologised. The other was a staring omission, and he had stated in his paper that he was conscious of omissions. The difficulty was to get everything into the time available and yet allow of discussion afterwards.

With regard to Dr. Price's remarks on the Wassermann, Kahn and Sigma tests, the question raised was, when one had a case which gave a negative Wassermann and a positive Kahn, what ought one to do ? Dr. Price said "Do a Sigma," and no doubt he was right. He, the 


\section{BRITISH JOURNAL OF VENEREAL DISEASES}

speaker, had done it thousands of times, and in treated cases of syphilis it was nearly always the Kahn test that was positive and the Wassermann negative. He did not think the Kahn test was Ioo per cent. specific in anybody's hands except those of Kahn himself. He, Dr. Osmond, had deliberately made the test somewhat over-sensitive, and therefore he did not bank entirely on the Kahn for diagnosis. He liked to have a sensitive test for judging as to cure.

He agreed thoroughly with what Dr. Price said concerning cell count.

In reply to Mr. King, if he would bring a case of active subacute arthritis with a negative c.d.t. done by Dr. Price, he would be prepared to bet that the case was not gonorrhœal.

In answer to Dr. Nicol concerning the primary sore, the earliest date he had met it was at seven days, and he thought those cases, nearly always, remained negative throughout treatment. But if one took a case of seronegative syphilis, which had been going on ten or twelve days, and then tested his blood daily for a week while he was under treatment, one would be surprised at the number of positives which turned up. A number of comparatively late primaries did that.

Colonel Harrison apparently refused to have greatness thrust upon him, but if that gentleman did not invent the fine needle, he at least introduced its use into St. Thomas's. $\mathrm{He}$, the speaker, knew, because taking of the cerebrospinal fluid was now more simple as the patients did not get headaches following it.

Dr. Nabarro had spoken of weak positives in congenital syphilis. He, Dr. Osmond, said in his paper that a weak positive should act as a stimulus to further investigation of the case, both clinical and serological.

With regard to pregnancy, he thought the President had clarified the situation.

As to the evidences of congenital syphilis, as the child got older, he said in the paper that the number of positive Wassermanns tended to diminish, and he still believed that if one took a large number of congenitally syphilitic children and tested their blood year by year, one would find more negatives in those of sixteen to eighteen years of age than in those of seven or eight years.

It was an omission on his part not to have mentioned 


\section{THE VALUE OF SERUM REACTIONS}

glandular fever ; that was rather prevalent a year or two ago, and patients with it gave positive Wassermanns. He did not see a case of it himself, therefore he had not had personal experience of it.

Dr. Anwyl Davies asked which test the speaker would do, a Kahn or a Wassermann; his reply was that he would do both. He had coming to him, from time to time, many medical men who were working abroad, and who said the Wassermann was a complicated test, and to them he gave the advice to do a Kahn. That was the policy in India, where there was a lot of trouble over the Wassermann; one could not get a good hæmolytic amboceptor, rabbits and guinea-pigs did not thrive, and one could not get a high titre complement. When he was in that country, shortly before the War, the pathologist attached to the Northern Army went to the hills in the hot weather to do his Wassermanns, because in the plains he could not get a decent complement.

With regard to Dr. Anwyl Davies' statement about the Wassermann-fast patient, he, Dr. Osmond, was very much surprised. He thought the man who had a patient who was Wassermann-fast and did not examine the cerebro-spinal fluid was a criminal. He had seen a number of these cases-comparatively old cases-of syphilis with positive cerebro-spinal fluids. If a man had had adequate treatment and his cerebro-spinal fluid was negative, he could get married, but if his fluid was positive he would not give that advice. One would not let a man with a positive fluid go on in the same way as one with a negative.

With regard to the old story of husband and wife, recently a doctor wrote the speaker and said " Jones" had an acute attack of gonorrhœa, and had one previously in October, with epididymitis, but it seemed to be clearing up, and asking that the wife be tested. She had some endocervicitis, and a complement-fixation was done on both. His was strongly positive, and the wife's was a. weak doubtful. The husband denied any extra-marital intercourse. The speaker's opinion was asked. This could be shortly expressed in regard to the man's tale : "Liar."

Mr. Buckley Sharp had raised the question of serumnegative secondary syphilis; that was a question which often cropped up, but cases of the kind were very rare. Those cases did not do well under treatment. 